\title{
Methylation of adenomatous polyposis coli $(A P C)$ gene promoter is a generalized feature on molecular pathology tests of sporadic renal cell carcinomas in Taiwan
}

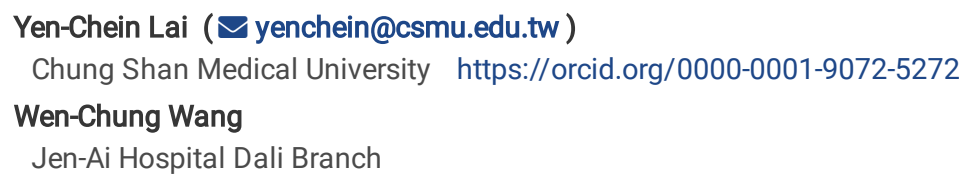

Research article

Keywords: Renal cell carcinoma, von Hippel-Lindau gene (VHL), tumor suppressor gene, methylation sensitive multiplex ligation-dependent probe amplification analysis,promoter methylation

Posted Date: October 9th, 2020

DOI: https://doi.org/10.21203/rs.3.rs-87466/v1

License: (c) (i) This work is licensed under a Creative Commons Attribution 4.0 International License. Read Full License 


\section{Abstract}

Background: Renal cell carcinoma (RCC) is the most common form of kidney cancer in adults. Approximately $50 \%$ to $80 \%$ of sporadic RCCs are associated with mutations in the von Hippel-Lindau (VHL) gene in Western countries. The aim of this study is to elucidate the possible etiological role of molecular pathogenesis in sporadic RCCs in Taiwan.

Methods: Fifteen patients with RCC were screened for mutations in the VHL gene and methylation statuses of promoters of 24 tumor suppressor genes. Mutations were identified by PCR and Sanger sequencing. Methylation statuses were determined on methylation sensitive multiplex ligation-dependent probe amplification (MS-MLPA) analysis.

Results: Inactivation of VHL gene was observed in 5 cases: three missense somatic mutations, V155G in case 1, N141S in case 5, and E52D in case 9; promoter methylation in case 3 ; and small deletion in case 13 . RCCs were most frequently methylated at $A P C(100 \%, 14 / 14), C D K N 2 B(92.9 \%, 13 / 14)$, CASP8, MLH1_167, and $K L L N(85.7 .4 \%, 12 / 14)$, but not at FHIT, MLH1_463, DAPK1, or HIC1 (0\%).

Conclusions: In addition to $V H L$ inactivation, promoter methylation of $A P C$ and $C D K N 2 B$ may play important roles in the tumorigenesis of RCC. Methylation of $A P C$ may be a very early pathognomonic event in tumorigenesis of RCC and a candidate diagnostic and therapeutic biomarker.

\section{Background}

Kidney cancer affects about 300,000 people worldwide and is responsible for 129,000 deaths annually [1]. The global age-standardized incidence rate is 4 per 100,000 people per year [2]. Moreover, age standardized incidence rate increased from 3.35/100,000 individuals in 2002 to 5.09/100,000 individuals in 2012 in Taiwan [3]. Renal cell carcinoma (RCC) is the most common form in adults, accounting for around $90 \%$ of all kidney cancer [4]. The incidence rates have increased over time in most populations, but mortality rates have levelled off or decreased since the 1990s [5]. Based on the 2016 WHO classification, the major subtypes are clear cell, papillary, and chromophobe, which comprise 65-70\%, 15-20\%, and 5-7\% of all RCCs, respectively [6]. Clear cell RCC accounts for most kidney cancer-related deaths and is characterized by cells with clear cytoplasm [7].

The genetic feature most closely associated with sporadic clear cell RCC is loss or mutation of the von Hippel-Lindau (VHL) tumor suppressor gene [810]. However, inactivation of $V H L$ alone is not sufficient to cause RCC [11, 12]. Other genes are likely to be important in its development including PBRM1 (29-41\% of tumor samples), SETD2 (8-12\%), BAP1 (6-10\%), KDM5C(4-7\%), and MTOR (5-6\%) [5]. Epigenetic inactivation of tumor suppressor genes by methylation of promoter region of $\mathrm{CpG}$ dinucleotides has also been implicated in the pathogenesis of RCC [13, 14]. Early studies have demonstrated that $V H L, C D K N 2 A / p 16 I N K 4 a$, and RASSF1A tumor suppressor genes are frequently inactivated by methylation in clear cell RCC [14, 15]. More recent studies have demonstrated tumor-specific promoter methylation of genes BNC1, PDLIM4, RPRM, CST6, SFRP1, GREM1, COL 14A1, and COL $15 A 1$ in more than $30 \%$ of RCCs [13].

The genetic aspects of RCC have received little attention in Taiwan. Acquired cystic disease-associated RCC has been reported to be associated with frequent abnormalities on chromosome 3 [16]. Yano et al. noted that the CpG islands of connexin 32 gene are methylated in RCCs of hemodialysis patients [17]. The aim of this study is to elucidate the possible etiological role of molecular pathogenesis in sporadic RCCs in Taiwan. A total of 15 patients with RCC were screened for mutations in the $V H L$ gene and methylation statuses in 24 tumor suppressor genes. Mutations were identified by PCR and Sanger sequencing. Methylation statuses were determined on methylation sensitive multiplex ligation-dependent probe amplification (MSMLPA) analysis.

\section{Methods}

\section{Study subjects}

Fifteen paraffin-embedded tumor and normal tissue samples (Cases 1 to 15, 8 males and 7 females, Table 1) were provided by the Tumor Tissue Bank of Koo Foundation Sun Yat-Sen Cancer Center which is funded by the National Science and Technology Program for Pharmaceuticals and Biotechnology (\#NSC89-2323-B-368-001). The study procedures were approved by the Institutional Review Board of Chung Shan Medical University Hospital (reference number CS2-03052). All procedures that involved human participants were conducted in accordance with the ethical standards of the institutional and/or national research committee and the 1964 Declaration of Helsinki and its later amendments or comparable ethical standards. 
Table 1

RCC patients with and without somatic inactivation of $V H L$ gene

\begin{tabular}{|c|c|c|c|c|c|c|c|c|}
\hline \multirow[b]{2}{*}{$\#$} & \multirow[b]{2}{*}{ Age } & \multirow[b]{2}{*}{ Stage } & \multirow[b]{2}{*}{ Clear cells } & \multirow[t]{2}{*}{ Inactivation of $V H L$ gene } & \multicolumn{2}{|c|}{ VHL Exon Mutation } & \multicolumn{2}{|l|}{ VHL Promoter } \\
\hline & & & & & Nucleotide & Protein & Tumor & Tumor/Normal \\
\hline 1 & $\geq 50$ & III & Yes & Yes & $677 \mathrm{~T}>\mathrm{G}$ & V155G & - & - \\
\hline 2 & $<50$ & I & Yes & ND & ND & ND & ND & ND \\
\hline 3 & $\geq 50$ & III & Yes & Yes & ND & ND & Hypermethylation & 1.88 \\
\hline 4 & $\geq 50$ & II & Yes & ND & ND & ND & ND & ND \\
\hline 5 & $\geq 50$ & I & Yes & Yes & $635 A>G$ & N141S & ND & ND \\
\hline 6 & $<50$ & I & Yes & ND & ND & ND & ND & ND \\
\hline 7 & $\geq 50$ & 1 & Yes & ND & $312 \mathrm{G}>\mathrm{T}$ & ND & ND & ND \\
\hline 8 & $\geq 50$ & III & Yes & ND & ND & ND & ND & ND \\
\hline 9 & $\geq 50$ & I & Yes & Yes & $369 \mathrm{G}>\mathrm{T}$ & E52D & ND & ND \\
\hline 10 & $\geq 50$ & II or III & Yes & ND & ND & ND & ND & ND \\
\hline 11 & $<50$ & I & Yes & Partial & ND & ND & CNR 0.478 & 0.904 \\
\hline 12 & $\geq 50$ & 1 & Yes & Partial & ND & ND & CNR 0.621 & 1.048 \\
\hline 13 & $\geq 50$ & II & Yes & Yes & ND & ND & Deletion & 0 \\
\hline 14 & $\geq 50$ & I & Yes & ND & ND & ND & CNR 0.734 & 0.956 \\
\hline 15 & $\geq 50$ & I & No & Partial & ND & ND & CNR 0.612 & 0.728 \\
\hline \multicolumn{9}{|c|}{ GenBank accession number NM_000551.3 for nucleotide and NP_000542.1 for amino acid. } \\
\hline \multicolumn{9}{|c|}{ ND, no somatic changes were detected. } \\
\hline \multicolumn{9}{|c|}{ Hypermethylation means that 5 normal reference DNA samples were unmethylated and tumor DNA samples were methylated. } \\
\hline
\end{tabular}

\section{DNA extraction}

Genomic DNA was extracted from the sections with the QIAamp Tissue Kit (Qiagen), according to the manufacturer's instructions and finally dissolved in $100 \mu \mathrm{l}$ of TE buffer (10 mM Tris-HCl, pH 8.0, and 1 mM EDTA). DNA concentration of each sample was measured using NanoDrop UV-VIS Spectrophotometer.

\section{Polymerase chain reaction (PCR) and direct sequencing}

The three exons of the $V H L$ gene were amplified in 7 fragments with published primers under published conditions (Additional File 1) [18]. PCR products were purified using QIAquick PCR Purification kits (Qiagen GmbH., Hilden, Germany). The purified PCR products were sequenced via the cycle sequencing method with fluorescently labelled dideoxy chain terminators from ABI Prism kit (Applied Biosystems, Taipei, Taiwan) in an ABI Model 377 automated DNA sequencer, according to the distributor's protocol. The sequencing primers were the same as those for the preceding PCRs. When a mutation was detected, the nucleotide sequence was confirmed on both strands.

\section{Copy number and methylation analyses}

MS-MLPA analysis was performed using Salsa MS-MLPA kit ME001-C2 Tumor suppressor-1 (MRC-Holland) according to the manufacturer's instructions. Samples were then subjected to capillary electrophoresis on an ABI PRISM 3130XL (Applied Biosystems). Twenty-six MS-MLPA probes were used to detect the methylation statuses of promoter regions of 24 different tumor suppressor genes by Hhal digestion (Additional File 2). MLPA results were analyzed using GeneMarker version 3.2.1 (SoftGenetics, LLC) to determine copy numbers and methylation statuses of the Hhal sites. For copy number, each sample peak area was divided by the nearest control peak areas. Relative copy number was obtained by comparing this ratio with that of a control sample [19]. The internal methylation ratio was calculated by comparison of the Hhal digested aliquot with the paired undigested aliquot from each sample with intra-sample data normalization according to the manufacturer's instructions [20]. Methylation, compared to normal reference, was assessed by comparing the probe methylation percentages obtained for the test sample with the percentages of the 5 normal reference samples. Copy number ratio of 1.0 and methylation ratio of 0 were expected in most genes in normal reference. If so, the methylation compared to normal reference was unlimited $(\infty)$. If methylation ratios of test sample and normal reference samples were appropriate, methylation compared to normal reference was around 1.0 . 


\section{Results}

\section{VHL gene inactivation: mutation and promoter methylation}

The DNA sequences of $V H L$ gene were determined via direct sequencing. Four mutations were identified in the exon region of $V H L$ gene in the DNA samples from paraffin-embedded tumor specimens (Table 1). Among them were three missense mutations. Valine was substituted for glycine via heterozygous mutation at codon 155 (V155L) in exon 3, 677T > G in case 1 (Fig. 1A); asparagine was substituted for serine via heterozygous mutation at codon 141 (N141S) in exon 2, 635A > G in case 5 (Fig. 1B); and glutamate was substituted for aspartate via heterozygous mutation at codon 52 (E52D) in exon 1, 369G > T in case 9 (Fig. 1D). There was one silent mutation, with no change in amino acid sequence, via heterozygous mutation at codon 33 in exon 1, 312G > A in case 7 (Fig. 1C).

MLPA results were analyzed to determine copy numbers and methylation statuses of the Hhal sites in the promoter region of $V H L$ gene located in chromosome 3p25.3 (Table 1). In case 3, methylation ratios were unlimited ( $\infty$ ) in both normal and tumor tissue DNA compared to average normal reference (Table 1, Fig. 2A and 2B). This indicated that the $V H L$ gene is inactivated by its promoter methylation in both germline and somatic DNA. Copy number ratio of 0 was detected in tumor somatic DNA from case 13 , and meaning that the $V H L$ probe failed to hybridize with its promoter region due to a small deletion (Table 1, Fig. 2E and 2F). In addition, partial inactivation of VHL gene was identified due to copy number ratio decreases in cases 11, 12, and 15 in both normal and tumor tissue DNA compared to average normal reference (Table 1).

\section{Copy number and methylation analyses}

MS-MLPA analysis was performed with DNA from case 2 to case 15 using Salsa MS-MLPA kit ME001-C2 Tumor suppressor-1. Increases in copy number ratio of CADM1 were found in all RCCs. Copy number ratios were 1.38, 1.40, 1.20, 1.29, 1.27, 1.37, 1.42, 1.26, 1.40, 1.30, 1.58, 1.43, 1.54 and 1.22 , respectively. For case 13 , in addition to the VHL gene, copy number ratio of 0 was detected in the FHIT gene indicating a small deletion (Fig. $2 \mathrm{E}$ and $2 \mathrm{~F})$.

Methylation of $A P C(100 \%)$ was found in all RCCs (Fig. 2, Table 2). The second most commonly methylated gene was $C D K N 2 B(92.9 \%)$. Only case 11 was found to be unmethylated. Methylation of CASP8 (not in case 11 or 13), MLH1_167 (not in case 2 or 11), and KLLN(not in case 13 or 14) was found in 12 out of 14 (85.7\%) RCCs (Table 2). Methylation of RASSF1_382 (not in case 2, 4, 6, or 11), CDH13 (not in case 8, 11, 13, or 14), and CDKN2A (not in cases 11 to 14) was found in 10 out of 14 (71.4\%) RCCs. Frequencies of 9 genes with medium level of methylation were $A T M 64.3 \%$, RASSF1_328 57.1\%, CD44 50.0\%, TP73 42.9\%, RARB, ESR1, and BRCA1 35.7\%, TIMP3 and GSTP1 28.6\%. Moreover, methylation of CDKN1B (case 12), $B R C A 2$ (case 12), and CADM1 (case 2) was identified in only one (7.1\%) RCC. Methylation of $C H F R$ was identified in only two RCCs, case 3 and case 8 . Twenty-one out of 26 MS-MLPA probes showed somatic DNA methylation only. CDKN2B, MLH1_167, CDH13, RASSF1_328 and RARB demonstrated germline DNA methylation (data not shown). Somatic DNA methylation means that methylation is found in RCC tissue only, not in their corresponding normal tissues. 
Table 2

RCC patients with and without methylation in the promoter of 24 tumor suppressor genes

\begin{tabular}{|c|c|c|c|c|c|c|c|c|c|c|c|c|c|c|c|}
\hline Size & Gene & \# 2 & \# 3 & $\# 4$ & $\# 5$ & $\# 6$ & \# 7 & $\# 8$ & \# 9 & \# 10 & \# 11 & \# 12 & \# 13 & \# 14 & \# 15 \\
\hline 148 & $A P C$ & 0.071 & 0.118 & 0.112 & 0.044 & 0.047 & 0.072 & 0.220 & 0.111 & 0.111 & 0.175 & 0.064 & 0.303 & 0.193 & 0.096 \\
\hline \multicolumn{16}{|l|}{ High } \\
\hline 211 & $C D K N 2 B$ & 0.128 & 0.107 & 0.228 & 0.159 & 0.261 & 0.122 & 0.137 & 0.174 & 0.163 & 0 & 0.091 & 0.438 & 0.182 & 0.161 \\
\hline 265 & CASP8 & 0.035 & 0.040 & 0.026 & 0.021 & 0.020 & 0.075 & 0.089 & 0.097 & 0.042 & 0 & 0.059 & 0 & 0.086 & 0.050 \\
\hline 167 & $M L H 1$ & 0 & 0.122 & 0.080 & 0.046 & 0.047 & 0.097 & 0.107 & 0.067 & 0.070 & 0 & 0.165 & 0.309 & 0.138 & 0.074 \\
\hline 292 & $K L L N$ & 0.083 & 0.056 & 0.063 & 0.040 & 0.055 & 0.060 & 0.045 & 0.034 & 0.032 & 0.297 & 0.081 & 0 & 0 & 0.049 \\
\hline 382 & RASSF1 & 0 & 0.378 & 0 & 0.319 & 0 & 0.174 & 0.183 & 0.180 & 0.384 & 0 & 0.650 & 0.376 & 0.296 & 1.084 \\
\hline 436 & $\mathrm{CDH13}$ & 0.077 & 0.139 & 0.098 & 0.048 & 0.048 & 0.047 & 0 & 0.080 & 0.065 & 0 & 0.221 & 0 & 0 & 0.070 \\
\hline 161 & $C D K N 2 A$ & 0.086 & 0.107 & 0.050 & 0.033 & 0.047 & 0.061 & 0.124 & 0.064 & 0.038 & 0 & 0 & 0 & 0 & 0.061 \\
\hline \multicolumn{16}{|c|}{ Medium } \\
\hline 184 & $A T M$ & 0 & 0.118 & 0.083 & 0 & 0 & 0.127 & 0.057 & 0.060 & 0.052 & 0 & 0 & 0.535 & 0.158 & 0.096 \\
\hline 328 & RASSF1 & 0 & 0.463 & 0 & 0.321 & 0 & 0.122 & 2.051 & 0.180 & 0.296 & 0 & 0.486 & 0 & 0 & 0.805 \\
\hline 319 & $C D 44$ & 0.135 & 0 & 0 & 0.175 & 0.147 & 0 & 0 & 0 & 0.041 & 0 & 0.073 & 0.160 & 0 & 0.075 \\
\hline 400 & TP73 & 0 & 0 & 0 & 0 & 0 & 0 & 0.113 & 0.075 & 0.088 & 0 & 0.080 & 0 & 0 & 0.131 \\
\hline 193 & $R A R B$ & 0 & 0 & 0.117 & 0.056 & 0 & 0 & 0.209 & 0.092 & 0.038 & 0 & 0 & 0 & 0 & 0 \\
\hline 373 & ESR1 & 0 & 0 & 0 & 0.107 & 0.097 & 0 & 0 & 0.113 & 0.189 & 0 & 0 & 0 & 0 & 0 \\
\hline 246 & $B R C A 1$ & 0 & 0 & 0 & 0 & 0.023 & 0 & 0.034 & 0.043 & 0 & 0 & 0.057 & 0 & 0 & 0 \\
\hline 142 & TIMP3 & 0 & 0.217 & 0 & 0 & 0 & 0 & 0.154 & 0.057 & 0.049 & 0 & 0 & 0 & 0 & 0 \\
\hline 454 & GSTP1 & 0 & 0 & 0 & 0 & 0 & 0 & 0 & 0.071 & 0.046 & 0 & 0.810 & 0 & 0 & 0.101 \\
\hline \multicolumn{16}{|l|}{ Low } \\
\hline 238 & CHFR & 0 & 0.327 & 0 & 0 & 0 & 0 & 0.069 & 0 & 0 & 0 & 0 & 0 & 0 & 0 \\
\hline 274 & CDKN1B & 0 & 0 & 0 & 0 & 0 & 0 & 0 & 0 & 0 & 0 & 0.090 & 0 & 0 & 0 \\
\hline 301 & BRCA2 & 0 & 0 & 0 & 0 & 0 & 0 & 0 & 0 & 0 & 0 & 0.115 & 0 & 0 & 0 \\
\hline 427 & CADM1 & 0.080 & 0 & 0 & 0 & 0 & 0 & 0 & 0 & 0 & 0 & 0 & 0 & 0 & 0 \\
\hline 409 & FHIT & 0 & 0 & 0 & 0 & 0 & 0 & 0 & 0 & 0 & 0 & 0 & $0 *$ & 0 & 0 \\
\hline 463 & MLH1 & 0 & 0 & 0 & 0 & 0 & 0 & 0 & 0 & 0 & 0 & 0 & 0 & 0 & 0 \\
\hline 346 & DAPK1 & 0 & 0 & 0 & 0 & 0 & 0 & 0 & 0 & 0 & 0 & 0 & 0 & 0 & 0 \\
\hline 220 & HIC1 & 0 & 0 & 0 & 0 & 0 & 0 & 0 & 0 & 0 & 0 & 0 & 0 & 0 & 0 \\
\hline
\end{tabular}

Four of the 24 genes (FHIT, MLH1_463, DAPK1, and HIC1) did not show detectable promoter region methylation (Table 2).

\section{Patient characteristics in relation to methylations statuses in tumor suppressor genes}

Age ( $\geq 50,<50$ ), clear cell type RCC (yes/no), and tumor stage (early, stage I and II; late, stage III to IV) are dichotomous variables based on Moore's work [21]. Pathological stage is an important determinant of survival. We found a novel and interesting correlation between methylation of the $C H F R$ gene promoter and late stage. No other gene associations for promoter methylation were found for age, or clear cell type RCC. RCC incidence is higher in men than in women [5]. However, there was no significant difference in the numbers of males and females in this study (8 males and 7 females).

\section{Discussion}

It has been suggested that the VHL tumor suppressor gene is a major gatekeeper gene for clear cell RCC [22]. About 50\%-80\% of sporadic RCCs are shown to have mutations of the $V H L$ gene $[23,24]$. In this study, which was conducted in Taiwan, the frequency of $V H L$ mutation events for sporadic 
RCCs was only $20 \%$ (3/15), which is much lower than in Western countries. Our results showed promoter hypermethylation in 1 of 15 (6.6\%) tumors. This ratio is also lower than that of a previous study in which silencing of the VHL gene by DNA methylation occurred in about 20\% of RCCs [10, 23]. Recently, it has been reported in the Cancer Genome Atlas that 7\% of clear cell RCCs showed epigenetic silencing at $V H L$ [7, 25]. The discrepancy may be attributed to ethnic effects. However, further studies using larger samples are recommended to verify our results. In the present study, both FHIT and $V H L$ deletions were found in case 13 (age $\geq 50$, stage II). A previous study has suggested that FHIT deletion is an early event and $V H L$ deletion as an early and/or late event in RCC [26].

Dulaimi et al. reported that the frequencies of hypermethylation in 100 kidney tumors were $R A S S F 1 A(45 \%), A P C(14 \%), R A R B 2(12 \%)$, CDKN2A/p16INK4a (10\%), and VHL (8\%) [14]. Morris et al. noted that RCCs are most frequently methylated at DAPK (24\%), not at RARB2 (0\%), CDKN2A/p16INK4a (0\%) or CDH13 (3\%) [27]. However, these results were not verified by this study as RCCs were found to be most frequently methylated at $A P C(100 \%), C D H 13(71.4 \%, 10 / 14), C D K N 2 A(71.4 \%, 10 / 14), R A R B 2(35.7 \%, 5 / 10)$, and $V H L(7.14 \%, 1 / 14)$, not at $D A P K 1(0 \%)$. Based on the results of this study, frequencies of promoter methylation in RASSF1A, 76.9\% (10/13) for RASSF1A_382, and 61.5\% (8/13) for RASSF1A_382, in $8 / 14$ cases were much higher than in previous studies in which RASSF1A promoter methylation was detected in $56 \%$ and $40 \%$ of primary clear cell RCCs, respectively $[28,29]$. In this study, neither germline nor somatic DNA methylations in DAPK1 were identified, which is inconsistent with the findings of a previous study [30]. The reasons for this discrepancy are unclear but may be related to the sensitivity of the methods used. With older molecular methods based on radio-labeled primers and polyacrylamide gel electrophoresis, small minor bands may be missed or mistaken. Capillary gel electrophoresis with fluorescence detection allows for the analysis of methylation status with high sensitivity. Dulaimi et al. also noted that RASSF1A methylation is significantly associated with high-grade tumors [14]. Recent studies have highlighted that $16 \%$ of RCC cases have loss of CDKN2A through mutation, deletion, or promoter hypermethylation [7, 31].

Although there were differential methylation patterns of the 24 tumor suppressor genes among the 14 RCCs, at least two (mean $=10.7$ ) genes were methylated in each tumor sample. In this study, all RCCs showed methylation of APC specific to RCC, not in normal tissues, which did not change with age. APC gene encodes a 312-kDa protein that acts as an antagonist of the Wnt signaling pathway [32]. Deregulation of Wnt signal pathway through $A P C$ deficiency or loss of heterozygosity has recently been implicated in human RCC [33-35]. Aberrant methylation of the APC gene promoter has been reported not only in colon [36], but also in breast and lung carcinomas [37]. The accumulation of a variety of genetic aberrations is necessary for the initiation and progression of RCCs [38]. These results indicated that methylation of $A P C$ is a very early pathognomonic event in tumorigenesis of RCC and can be a candidate diagnostic and therapeutic biomarker as it is found early in the process of carcinogenesis.

In addition to $A P C$ methylation, there were a variety of other genetic aberrations. $C D K N 2 B$ gene methylation was observed in all RCCs, except for case 11. $C D K N 2 B$ gene on $9 \mathrm{p} 21.3$ encodes the $\mathrm{p} 15^{\mathrm{INK} 4 \mathrm{~B}}$ protein that binds to and inhibits activation of CDK4 or CDK6 [39]. Germline mutations in $C D K N 2 B$ have been identified as a novel cause of familial RCC [40]. CASP8 gene encodes Caspase-8 that is an apoptosis-related cysteine peptidase [41]. Methylation at CASP8 has been demonstrated in 16\% of RCCs [27]. MLH1 gene encodes proteins that detect and repair DNA mismatches [42]. Expression of mismatch repair proteins MLH1 has been shown to be reduced in $83.7 \%(118 / 141)$ of sporadic RCCs [43]. KLLN gene encodes the protein killin, which is a p53-regulated nuclear inhibitor of DNA synthesis [44]. Bennett el al. found germline methylation in 23/41 (56\%) RCC patients and somatic methylation in 19/20 (95\%) advanced RCC patients [45]. These results indicated that methylation of $A P C, C D K N 2 B, C A S P 8, M L H 1 \_167$, and $K L L N$ is important in the tumorigenesis of RCC, which may inform its diagnostic, clinical, and therapeutic management.

\section{Conclusions}

Inactivation of $V H L$ gene was observed in 5 cases: three missense somatic mutations, V155G in case 1, N141S in case 5, and E52D in case 9, promoter methylation in case 3 , and small deletion in case 13. RCCs were most frequently methylated at $A P C(100 \%, 14 / 14), C D K N 2 B(92.9 \%, 13 / 14), C A S P 8$, MLH1_167, and $K L L N(85.7 .4 \%, 12 / 14)$, but not at FHIT, MLH1_463, DAPK1, and HIC1 (0\%). Rate of VHL inactivation and promoter methylation profile for RCCs in the Taiwanese population differ from those in Western populations. This may be attributed to ethnic effects. However, larger sample size is required to confirm these finding. Moreover, methylation of $A P C$ may be a very early pathognomonic event in tumorigenesis of RCC and a candidate diagnostic and therapeutic biomarker.

\section{Abbreviations}

$A P C$. adenomatous polyposis coli; BRCA1: breast cancer 1; BRCA2: breast cancer 2; CASP8: Caspase 8; CDKN2A: cyclin dependent kinase Inhibitor 2A; CDKN2B: cyclin dependent kinase Inhibitor 2B; CHFR: Checkpoint with forkhead and ring finger domains; DNA: deoxyribonucleic acid; FHIT: fragile histidine triad protein; HIC1: hypermethylated-in-cancer 1; KLLN: killin; KDM6A: lysine (K)-specific demethylase 6A; MLH1: mutL homolog 1; MS-MLPA: methylation-specific multiplex ligation-dependent probe amplification; NT: nucleotide; PBRM1: polybromol; RARB2: retinoic acid receptor B2; RASSF1: ras-association domain family member 1; RCC: renal cell carcinoma; SETD2: SET domain containing 2; UV-VIS: ultraviolet-visible; VHL: von HippelLindau.

\section{Declarations}

Acknowledgments: 
Tissue samples were provided by the Tumor Tissue Bank of Koo Foundation Sun Yat-Sen Cancer Center which is funded by the National Science and Technology Program for Pharmaceuticals and Biotechnology (\#NSC89-2323-B-368-001). The authors would like to thank GenePhile Bioscience Laboratory of Ko's Obstetrics and Gynecology Clinic for help with acquisition of data.

\section{Authors' contributions}

YCL designed the experiments, performed the experiments, interpreted the results, and drafted the manuscript. WWC designed the experiments, interpreted the results and made critical revisions to the manuscript. All authors have read and approved the final manuscript.

\section{Funding:}

Funding information is not applicable / No funding was received.

\section{Availability of data and materials}

The datasets used and/or analyzed during the current study are available from the corresponding author on reasonable request.

\section{Ethics approval and consent to participate}

Ethics approval of the study procedures was obtained from the Institutional Review Board of Chung Shan Medical University Hospital via reference number CS-03052. As no patients were involved and no personal information was used, informed consent was not applicable.

\section{Consent for publication}

Not applicable.

\section{Competing interest}

The authors declare that they have no competing interests.

\section{References}

1. Ferlay J, Soerjomataram I, Dikshit R, Eser S, Mathers C, Rebelo M, et al. Cancer incidence and mortality worldwide: sources, methods and major patterns in GLOBOCAN 2012. Int J Cancer. 2015;136(5):E359-86.

2. Ridge CA, Pua BB, Madoff DC. Epidemiology and staging of renal cell carcinoma. Semin Intervent Radiol. 2014;31(1):3-8.

3. Chiang CJ, Lo WC, Yang YW, You SL, Chen CJ, Lai MS. Incidence and survival of adult cancer patients in Taiwan, 2002-2012. J Formos Med Assoc. 2016;115(12):1076-88.

4. Ljungberg B, Campbell SC, Choi HY, Jacqmin D, Lee JE, Weikert S, et al. The epidemiology of renal cell carcinoma. Eur Urol. 2011;60(4):615-21.

5. Hsieh JJ, Purdue MP, Signoretti S, Swanton C, Albiges L, Schmidinger M, et al. Renal cell carcinoma. Nat Rev Dis Primers. $2017 ; 3: 17009$.

6. Inamura, K., Renal cell tumors: understanding their molecular pathological epidemiology and the 2016 WHO classification. Int J Mol Sci. 2017;18(10):2195

7. Lasseigne BN, Brooks JD. The role of DNA methylation in renal cell carcinoma. Mol Diagn Ther. 2018;22(4):431-42.

8. Jonasch E, Gao J, Rathmell WK. Renal cell carcinoma. BMJ. 2014;349:g4797.

9. Latif F, Tory K, Gnarra J, Yao M, Duh FM, Orcutt ML, et al. Identification of the von Hippel-Lindau disease tumor suppressor gene. Science. 1993;260(5112):1317-20.

10. Herman JG, Latif F, Weng Y, Lerman MI, Zbar B, Liu S, et al. Silencing of the VHL tumor-suppressor gene by DNA methylation in renal carcinoma. Proc Natl Acad Sci USA. 1994;91(21):9700-4.

11. Petejova N, Martinek A. Renal cell carcinoma: Review of etiology, pathophysiology and risk factors. Biomed Pap Med Fac Univ Palacky Olomouc Czech Repub. 2016;160(2):183-94.

12. Rankin EB, Tomaszewski JE, Haase VH. Renal cyst development in mice with conditional inactivation of the von Hippel-Lindau tumor suppressor. Cancer Res. 2006;66(5):2576-83.

13. Morris MR, Ricketts C, Gentle D, Abdulrahman M, Clarke N, Brown M, et al. Identification of candidate tumour suppressor genes frequently methylated in renal cell carcinoma. Oncogene. 2010;29(14):2104-17.

14. Dulaimi E, Ibanez de Caceres I, Uzzo RG, Al-Saleem T, Greenberg RE, Polascik TJ, et al. Promoter hypermethylation profile of kidney cancer. Clin Cancer Res. 2004;10(12):3972-9.

15. Clifford SC, Prowse AH, Affara NA, Buys CH, Maher ER. Inactivation of the von Hippel-Lindau (VHL) tumour suppressor gene and allelic losses at chromosome arm $3 p$ in primary renal cell carcinoma: evidence for a VHL-independent pathway in clear cell renal tumourigenesis. Genes Chromosomes Cancer. 1998;22(3):200-9. 
16. Pan CC, Chen YJ, Chang LC, Chang YH, Ho DM. Immunohistochemical and molecular genetic profiling of acquired cystic disease-associated renal cell carcinoma. Histopathology. 2009;55(2):145-53.

17. Yano T, Ito F, Kobayashi K, Yonezawa Y, Suzuki K, Asano R, et al. Hypermethylation of the CpG island of connexin 32, a candiate tumor suppressor gene in renal cell carcinomas from hemodialysis patients. Cancer Lett. 2004;208(2):137-42.

18. Wang WC, Chen HJ, Tseng YH, Lai YC. Identification of somatic mutations in the von Hippel-Lindau (VHL) gene in a patient with renal cell carcinoma. J Formos Med Assoc. 2009;108(11):886-93.

19. Nygren AO, Ameziane N, Duarte HM, Vijzelaar RN, Waisfisz Q, Hess CJ et al. Methylation-specific MLPA (MS-MLPA): simultaneous detection of CpG methylation and copy number changes of up to 40 sequences. Nucleic Acids Res. 2005;33(14):e128.

20. Homig-Holzel C, Savola S. Multiplex ligation-dependent probe amplification (MLPA) in tumor diagnostics and prognostics. Diagn Mol Pathol. 2012;21(4):189-206.

21. Moore LE, Nickerson ML, Brennan P, Toro JR, Jaeger E, Rinsky J, et al. Von Hippel-Lindau (VHL) inactivation in sporadic clear cell renal cancer: associations with germline VHL polymorphisms and etiologic risk factors. PLoS Genet. 2011;7(10):e1002312.

22. Martinez A, Fullwood P, Kondo K, Kishida T, Yao M, Maher ER, et al. Role of chromosome 3p12-p21 tumour suppressor genes in clear cell renal cell carcinoma: analysis of VHL dependent and VHL independent pathways of tumorigenesis. Mol Pathol. 2000;53(3):137-44.

23. Cowey CL, Rathmell WK. VHL gene mutations in renal cell carcinoma: role as a biomarker of disease outcome and drug efficacy. Curr Oncol Rep. 2009;11(2):94-101.

24. Razafinjatovo C, Bihr S, Mischo A, Vogl U, Schmidinger M, Moch H, et al. Characterization of VHL missense mutations in sporadic clear cell renal cell carcinoma: hotspots, affected binding domains, functional impact on pVHL and therapeutic relevance. BMC Cancer. 2016;16:638.

25. Cancer Genome Atlas Research Network. Comprehensive molecular characterization of clear cell renal cell carcinoma. Nature. 2013;499(7456):439.

26. Bhat Singh RR, Amare Kadam PS. Investigation of recurrent deletion loci specific to conventional renal cell carcinoma by comparative allelotyping in major epithelial carcinomas. Indian J Urol. 2012;28(1):47-52.

27. Morris MR, Hesson LB, Wagner KJ, Morgan NV, Astuti D, Lees RD, et al. Multigene methylation analysis of Wilms' tumour and adult renal cell carcinoma. Oncogene. 2003;22(43):6794-801.

28. Yoon JH, Dammann R, Pfeifer G.P. Hypermethylation of the $\mathrm{CpG}$ island of the RASSF1A gene in ovarian and renal cell carcinomas. Int $\mathrm{J}$ Cancer. 2001;94(2):212-7.

29. Tokinaga K, Okuda H, Nomura A, Ashida S, Furihata M, Shuin T. Hypermethylation of the RASSF1A tumor suppressor gene in Japanese clear cell renal cell carcinoma. Oncol Rep. 2004;12(4):805-10.

30. Christoph F, Kempkensteffen C, Weikert S, Kollermann J, Krause H, Miller K, et al. Methylation of tumour suppressor genes APAF-1 and DAPK-1 and in vitro effects of demethylating agents in bladder and kidney cancer. Br J Cancer. 2006;95(12):1701-7.

31. Ricketts CJ, De Cubas AA, Fan H, Smith CC, Lang M, Reznik E, et al. The Cancer Genome Atlas comprehensive molecular characterization of renal cell crcinoma. Cell Rep. 2018;23(1):313-326.e5.

32. Zhan T, Rindtorff N, Boutros M. Wnt signaling in cancer. Oncogene. 2017;36(11):1461-73.

33. Sansom OJ, Griffiths DF, Reed KR, Winton DJ, Clarke AR. Apc deficiency predisposes to renal carcinoma in the mouse. Oncogene. 2005;24(55):8205-10.

34. Pecina-Slaus N, Pavelic K, and Pavelic J. Loss of heterozygosity and protein expression of APC gene in renal cell carcinomas. J Mol Med (Berl). 1999;77(5):446-53.

35. Shenoy N, Vallumsetla N, Zou Y, Galeas JN, Shrivastava M, Hu C, et al. Role of DNA methylation in renal cell carcinoma. J Hematol Oncol. 2015;8:88.

36. Li BQ, Liu PP, Zhang CH. Correlation between the methylation of APC gene promoter and colon cancer. Oncol Lett. 2017;14(2):2315-19.

37. Virmani AK, Rathi A, Sathyanarayana UG, Padar A, Huang CX, Cunnigham HT, et al. Aberrant methylation of the adenomatous polyposis coli (APC) gene promoter 1A in breast and lung carcinomas. Clin Cancer Res. 2001;7(7):1998-2004.

38. Yoshida O, Habuchi T, Kinoshita H, Ogawa O. Oncogenes in Renal Cell Carcinoma. In: Biology of Renal Cell Carcinoma. New York: Springer; 1995. p. 26-32.

39. Roussel MF. The INK4 family of cell cycle inhibitors in cancer. Oncogene. 1999;18(38):5311-7.

40. Jafri M, Wake NC, Ascher DB, Pires DE, Gentle D, Morris MR, et al. Germline Mutations in the CDKN2B Tumor Suppressor Gene Predispose to Renal Cell Carcinoma. Cancer Discov. 2015;5(7):723-9.

41. Kruidering M, Evan GI. Caspase-8 in apoptosis: the beginning of "the end"? IUBMB Life. 2000;50(2):85-90.

42. Hsieh P, Yamane K. DNA mismatch repair: molecular mechanism, cancer, and ageing. Mech Ageing Dev. 2008;129(7-8):391-407.

43. Stoehr C, Burger M, Stoehr R, Bertz S, Ruemmele P, Hofstaedter F, et al. Mismatch repair proteins hMLH1 and hMSH2 are differently expressed in the three main subtypes of sporadic renal cell carcinoma. Pathobiology. 2012;79(3):162-8.

44. Cho YJ, Liang P. Killin is a p53-regulated nuclear inhibitor of DNA synthesis. Proc Natl Acad Sci USA. 2008;105(14):5396-401. 
45. Bennett KL, Campbell R, Ganapathi S, Zhou M, Rini B, Ganapathi R, et al. Germline and somatic DNA methylation and epigenetic regulation of KILLIN in renal cell carcinoma. Genes Chromosomes Cancer. 2011;50(8):654-61

Figures

A

A G A G TA TAC $\underset{1}{\nabla} C T G G A A G G \stackrel{B_{C A T C T C T C A}}{\nabla} T G T T G A C G($ 677
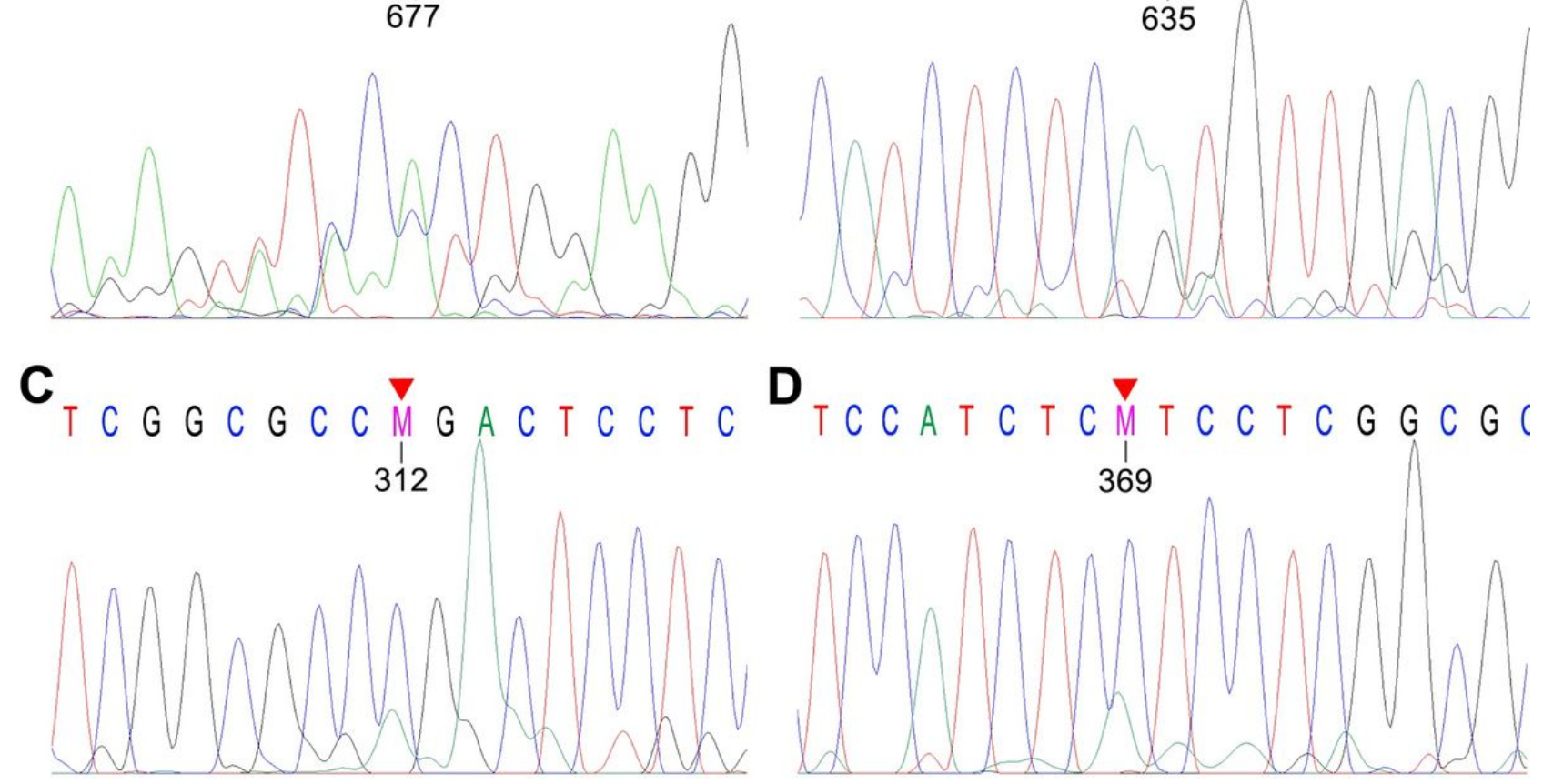

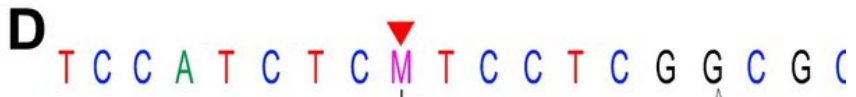

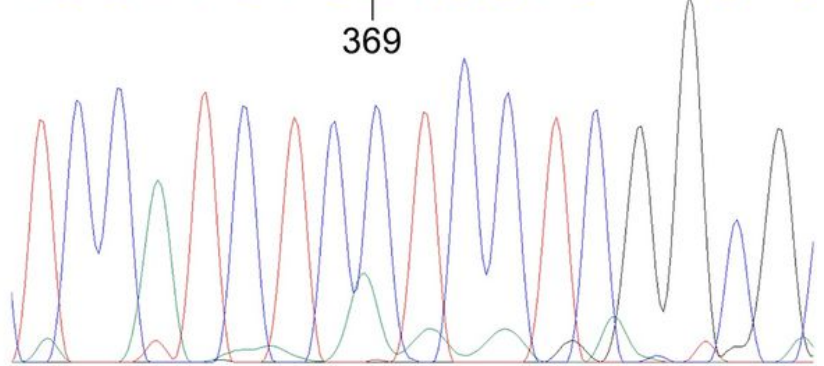

Figure 1

Partial sequencing chromatograms represent the genetic profiles of fragment 5 in reverse directions from case 1 (A), fragment 4 in forward directions from case 5 (B), and fragment 2 in reverse directions from case 7 (C) and case 9 (D), respectively. The mutated nucleotides are marked with a red arrow. 

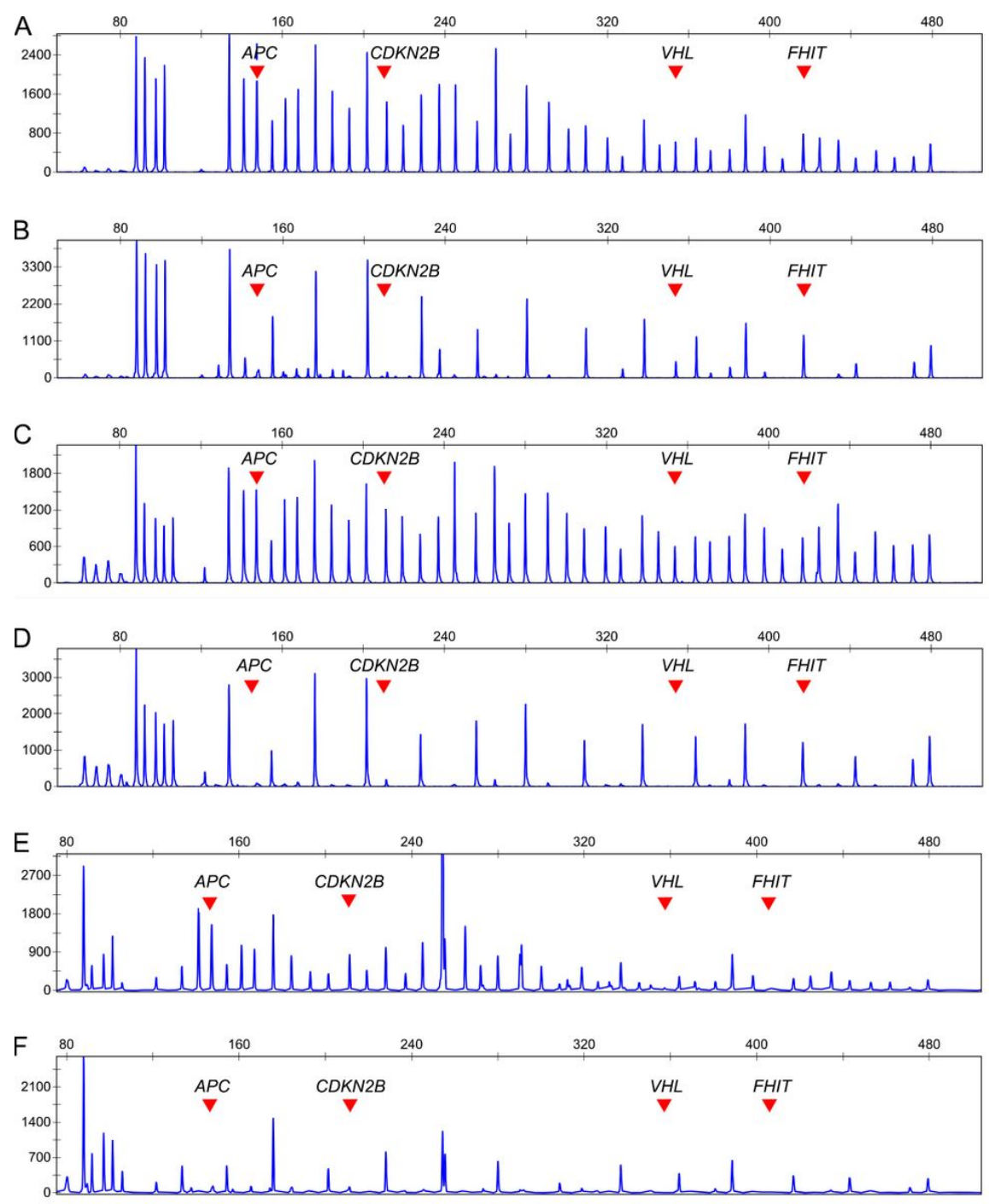

\section{Figure 2}

Detection of the methylation statuses of 24 different tumor suppressor genes in RCCs by MS-MLPA. The capillary electrophoresis pattern was observed from undigested DNA of case $3(A)$, case 7 (C), and case $13(E)$ and from the same sample but digested with Hhal site (B, D, F). Red arrows indicate fragment locations of $A P C, C D K N 2 B, V H L$, and FHIT.

\section{Supplementary Files}

This is a list of supplementary files associated with this preprint. Click to download.

- AdditionalFile1.docx

- AdditionalFile2.docx 